\title{
Antenatal exposure to Ureaplasma species exacerbates bronchopulmonary dysplasia synergistically with subsequent prolonged mechanical ventilation in preterm infants
}

\author{
Tadashi Inatomi', Shinya Oue', Tohru Ogihara', Seigo Hira' ${ }^{1}$, Masashi Hasegawa', Shigeo Yamaoka', Masako Yasui' and \\ Hiroshi Tamai'
}

INTRODUCTION: The presence of microorganisms in gastric fluid in neonates at birth is postulated to reflect antenatal infection and also to be associated with the development of bronchopulmonary dysplasia (BPD).

RESULTS: A logistic regression analysis, after controlling for other risk factors, indicated that Ureaplasma-positive infants were not at increased risk for moderate/severe BPD (adjusted odds ratio (OR): 2.58, 95\% confidence interval (Cl): 0.57-6.89, $P=0.12$ ). However, the association between the presence of Ureaplasma species and the risk for moderate/severe BPD increased significantly in infants on mechanical ventilation (MV) $\geq 2$ wk (adjusted OR: 4.17, 95\% Cl: 1.62-44.1, P=0.009). An analysis using a lung injury marker indicated that Ureaplasmapositive infants with $M V \geq 2 w k$, but not other infants, showed higher serum KL-6 levels in samples taken from cord blood, and that KL-6 levels increased time-dependently up to 4 wk of age. DISCUSSION: Antenatal exposure to Ureaplasma species induces lung injury prior to birth and synergistically contributes to the development of BPD in infants requiring prolonged MV ( $\geq 2 \mathrm{wk})$.

METHODS: We recovered gastric fluid specimens from 122 infants with gestational age (GA) $<29$ wk or birth weight $<1,000$ $g$ to investigate whether these microorganisms influence respiratory outcome of BPD. A PCR analysis was used to detect urease and 165 ribosomal RNA (rRNA) genes to classify neonates into Ureaplasma-positive or Ureaplasma-negative infants.

B ronchopulmonary dysplasia (BPD) is a common disorder that affects morbidity and mortality rates in premature infants. BPD has been associated with lung injury and inflammation resulting from oxygen toxicity, barotrauma/volutrauma, and infection in the premature lung $(1,2)$. In particular, over the past 2 decades, the level of evidence has increased regarding the existence of a link between intrauterine infection and BPD (3-5).

Ureaplasma species represent one of the most prevalent microbial causes of intrauterine and neonatal respiratory infection $(6,7)$. The presence of Ureaplasma species in the maternal upper genital tract or in the neonatal airway has a close relationship with adverse neonatal outcomes including preterm delivery and the development of BPD (7-11). On the other hand, exposure to antenatal infection or inflammation triggered by bacteria other than Ureaplasma species may also have an important pathogenic role in the development of BPD (12-14). In an experimental model, the intra-amniotic injection of lipopolysaccharide induced an inflammatory response that caused deterioration in the lung architecture of premature animals in combination with mechanical ventilation (MV) (14).

Miralles et al. reported that the presence of a bacterial $16 \mathrm{~S}$ ribosomal RNA (rRNA) gene in gastric fluid at birth was correlated with antenatal infection, thereby indicating that gastric fluid samples obtained from neonates soon after birth could be used as an alternative specimen to reflect antenatal infection (15). We recently found that the presence of a bacterial 16S rRNA gene in gastric fluid in infants was associated with the development of severe BPD (16). A biochemical analysis showed that, in a group of infants who tested positive for bacteria in gastric fluid at birth, the levels of KL-6, a lung injury marker, were high. This indication of lung injury was associated with an increased severity of subsequent BPD. Because KL-6 is a mucinous glycoprotein that is expressed by alveolar type II cells and bronchiolar cells and is known to be specifically correlated with the severity of respiratory distress in infants with BPD, increased plasma KL-6 levels at birth are presumed to be due to injury in the immature lungs resulting in the subsequent development of $\operatorname{BPD}(17,18)$. However, we could not clarify precisely which microorganism was most likely to play a pathogenic role in the ongoing process of BPD.

In this study, we investigated whether (i) antenatal exposure to Ureaplasma species, bacteria other than Ureaplasma species, or both, have a close association with the development of BPD; (ii) whether this association, if present, is modulated by postnatal lung injury induced by MV; and, if so, (iii) to what extent these microorganisms influence the respiratory morbidity associated with BPD. 


\section{RESULTS}

During the study period, 136 infants with gestational age (GA) $<29 \mathrm{wk}$ or a birth weight $<1,000 \mathrm{~g}$ were admitted to our units. Among them, seven infants did not qualify for enrollment in our study at birth (two had chromosomal anomalies, two had multiple congenital anomalies, and three had complicated congenital heart diseases). In addition, data relating to seven infants were excluded from the final analysis: five of these infants were transferred to other facilities, and gastric fluid or blood specimens were not obtained from two infants. In total, data relating to 122 infants ( $90 \%$ of all the eligible infants) were included in this study.

Of the total number of study infants, 35 (29\%) tested positive for Ureaplasma species in the gastric fluid soon after birth and were assigned to the Ureaplasma-positive group; 87 infants (71\%) were assigned to the Ureaplasma-negative group. Among the group of Ureaplasma-negative infants, 31 (25\% of the study infants) were positive for the $16 \mathrm{~S}$ rRNA gene and were therefore assigned to the bacteria-positive subgroup, whereas the other 56 infants in the group (46\% of the study infants) were negative for the $16 \mathrm{~S}$ rRNA gene and were therefore assigned to the bacteria-negative subgroup.

Clinical characteristics and outcomes were compared among all the study infants (Table 1). The mean GA in Ureaplasmapositive infants was significantly lower than the mean GA values in both bacteria-negative infants ( 26.4 vs. $27.9 \mathrm{wk}, P=0.009$ ) and bacteria-positive infants (26.4 vs. $27.7 \mathrm{wk}, P=0.013$ ). As compared with bacteria-negative infants, the incidence of chorioamnionitis was significantly higher in Ureaplasma-positive infants (bacteria-negative vs. Ureaplasma-positive: 11 vs. 79\%, $P<0.0001$ ) and in bacteria-positive infants (bacteria-negative vs. bacteria-positive: 11 vs. $63 \%, P=0.0001)$. The proportion of grade 2 or 3 chorioamnionitis was also higher in the Ureaplasmapositive infants (bacteria-negative vs. Ureaplasma-positive: 3.8 vs. $64 \%, P<0.0001$ ) and in bacteria-positive infants (bacteria-negative vs. bacteria-positive; 3.8 vs. $23 \%, P=0.012$ ).

Table 1 Comparison of the clinical characteristics and outcomes among Ureaplasma-negative infants (bacteria-negative infants, bacteriapositive infants) and Ureaplasma-positive infants

\begin{tabular}{|c|c|c|c|c|}
\hline & \multicolumn{2}{|c|}{ Ureaplasma-negative $(n=87)$} & \multicolumn{2}{|c|}{ Ureaplasma-positive $(n=35)$} \\
\hline & Bacteria-negative $(n=56)$ & Bacteria-positive $(n=31)$ & & $P$ value \\
\hline Male:female & $29: 27$ & $14: 17$ & 18:17 & 0.76 \\
\hline $\mathrm{GA}(w k)$ & $27.9(23.7$ to 31.1$)$ & 27.7 (24.4 to 31.9$)$ & $26.4(23.0 \text { to } 29.7)^{\mathrm{a}, \mathrm{b}}$ & 0.0001 \\
\hline BW (g) & 930 (376 to 1,626$)$ & $926(460$ to 1,420$)$ & $862(470$ to 1,410$)$ & 0.089 \\
\hline$Z$ score & 0 (-2.7 to 2.0$)$ & $0.20(-2.9$ to 1.8$)$ & $-0.10(-1.6$ to 1.5$)$ & 0.39 \\
\hline Apgar 1 min & 5 (1 to 9$)$ & 5 (1 to 9$)$ & $4(1 \text { to } 8)^{a, b}$ & 0.042 \\
\hline Apgar 5 min & $8(2$ to 10$)$ & $7(2$ to 10$)$ & 7 (3 to 9 ) & 0.27 \\
\hline $\mathrm{CS}, n(\%)$ & $49(88 \%)$ & $24(77 \%)$ & $19(54 \%)^{a}$ & 0.001 \\
\hline Antenatal steroid, $n(\%)$ & $38(68 \%)$ & $16(55 \%)$ & $24(69 \%)$ & 0.36 \\
\hline Chorioamnionitis, $n / N(\%)^{c}$ & $6 / 53(11 \%)$ & $19 / 30(63 \%)^{a}$ & $26 / 33(79 \%)^{a}$ & $<0.0001$ \\
\hline Chorioamnionitis $\geq$ grade $2, n / N(\%)^{c}$ & $2 / 53(3.8 \%)$ & $7 / 30(23 \%)^{a}$ & $21 / 33(64 \%)^{a}$ & $<0.0001$ \\
\hline $\mathrm{RDS}, n(\%)$ & $40(69 \%)$ & $20(65 \%)$ & $22(63 \%)$ & 0.74 \\
\hline PDA, $n(\%)$ & $28(48 \%)$ & $11(35 \%)$ & $16(46 \%)$ & 0.33 \\
\hline Sepsis, $n(\%)$ & $1(1.7 \%)$ & $1(3.2 \%)$ & $3(8.6 \%)$ & 0.48 \\
\hline Pneumonia, $n(\%)$ & $4(6.9 \%)$ & $2(6.5 \%)$ & $3(8.6 \%)$ & 0.92 \\
\hline Death due to lung disease & $2(3.4 \%)$ & $0(0 \%)$ & $1(2.8 \%)$ & 0.97 \\
\hline Death at PMA 36 wk & $2(3.4 \%)$ & $0(0 \%)$ & $2(4.5 \%)$ & 0.93 \\
\hline Supplemental oxygen (d) & 38 (0 to 146$)$ & 38 (2 to 219$)$ & 58 (0 to 200$)$ & 0.27 \\
\hline Mechanical ventilation, $n(\%)$ & $43(77 \%)$ & $24(77 \%)$ & $30(86 \%)$ & 0.89 \\
\hline Mechanical ventilation (d) & 5 (0 to 146$)$ & 8 (0 to 67$)$ & $16(0 \text { to } 129)^{a}$ & 0.046 \\
\hline Postnatal steroid, $n(\%)$ & $1(1.8 \%)$ & $2(6.5 \%)$ & $4(11.4 \%)$ & 0.098 \\
\hline $\mathrm{BPD}, n(\%)$ & $33(57 \%)$ & $22(71 \%)$ & $28(80 \%)^{\mathrm{a}}$ & 0.019 \\
\hline Mild BPD, $n(\%)$ & $24(41 \%)$ & $16(52 \%)$ & $14(40 \%)$ & 0.45 \\
\hline Moderate BPD, $n(\%)$ & $10(18 \%)$ & $3(9.7 \%)$ & $8(23 \%)$ & 0.75 \\
\hline Severe BPD, $n(\%)$ & $1(1.7 \%)$ & $3(9.7 \%)$ & $6(17 \%)^{a}$ & 0.010 \\
\hline Moderate/severe BPD, $n$ (\%) & $11(16 \%)$ & $6(19 \%)$ & $14(40 \%)^{a}$ & 0.005 \\
\hline
\end{tabular}

Values are expressed as the median (total range), or occurrences (\%). The $P$ value indicates the differences among three groups as analyzed by the Kruskal-Wallis or $X^{2}$ tests. BPD, bronchopulmonary dysplasia; BW, birth weight; CS, cesarean section; GA, gestational age; PDA, patent ductus arteriosus; PMA, postmenstrual age; RDS, respiratory distress syndrome. a $P<0.05$ vs. bacteria-negative infants. ${ }^{b} P<0.05$ vs. bacteria-positive infants. ${ }^{C H}$ Histologic examination of placentas obtained from 53 of 56 bacteria-negative infants, 33 of 35 Ureaplasma-positive infants, and 30 of 31 bacteria-positive infants. 
The occurrence of BPD in Ureaplasma-positive infants was significantly greater than in the bacteria-negative infants ( 80 vs. $57 \%, P=0.014$ ). The analysis of BPD severity indicated that, in comparing Ureaplasma-positive infants with bacteria-negative ones, the difference in occurrence was more prominent with respect to moderate/severe BPD (40 vs. $16 \%$, respectively, $P=0.002)$ and severe $\mathrm{BPD}(17 \mathrm{vs.} 1.7 \%$, respectively, $P=0.020$ ).

Predictor variables for the development of moderate/severe BPD were analyzed using univariate analysis (Table 2). Several factors emerged as significant predictors of moderate/severe BPD. Younger GA, lower birth weight, lower $Z$ score, the occurrence of respiratory distress syndrome (RDS), and the presence of $\mathrm{MV} \geq 2$ wk were all factors indicating a higher likelihood of developing moderate/severe BPD. The presence of Ureaplasma species was also a risk factor for moderate/severe BPD (odds ratio (OR): $2.75,95 \%$ confidence interval (CI): 1.72-9.80, $P=$ 0.006), but not the presence of bacteria other than Ureaplasma species. Therefore, further analyses were restricted to the comparison of clinical data from Ureaplasma-positive infants and Ureaplasma-negative infants.

Logistic-regression models were created to assess significant predictors of the development of moderate/severe BPD in the study infants. As shown in Table 3, a lower GA, smaller $Z$ score, and $M V \geq 2$ wk were independent risk factors for moderate/severe BPD. The adjusted OR (aOR) of Ureaplasma species for the development of moderate/severe BPD was slightly higher, and tended to be positively correlated with moderate/ severe $\mathrm{BPD}$, although the correlation was not significant (aOR: 2.58, 95\% CI: $0.57-6.89, P=0.12$ ). To examine whether antenatal exposure to Ureaplasma species had an interaction with $\mathrm{MV}$, the risk of developing moderate/severe BPD was compared among the Ureaplasma-negative group $\times \mathrm{MV}<2 \mathrm{wk}$ $(n=59)$, the Ureaplasma-positive group $\times \mathrm{MV}<2 \mathrm{wk}(n=18)$, the Ureaplasma-negative group $\times \mathrm{MV} \geq 2 \mathrm{wk}(n=28)$, and the Ureaplasma-positive group $\times \mathrm{MV} \geq 2 \mathrm{wk}(n=17)$, after controlling for other risk factors. This analysis showed that the risk for the Ureaplasma-positive group $\times \mathrm{MV} \geq 2$ wk was significantly higher than those for the Ureaplasma-negative group $\times$ MV <2 wk (aOR: 8.95, 95\% CI: 2.12-73.5, $P=0.001$ ) and the Ureaplasma-negative group $\times \mathrm{MV} \geq 2 \mathrm{wk}$ (aOR: $4.17,95 \% \mathrm{CI}$ : 1.62-44.1, $P=0.009$ ) (Table 4).

The time-dependent changes in KL-6 levels were compared among Ureaplasma-positive infants $(n=35)$, bacteria-positive infants $(n=31)$, and bacteria-negative infants $(n=56)$ of $<4$ wk of age (Figure 1). This analysis was performed on data within the respective groups for $\mathrm{MV} \geq 2 \mathrm{wk}$ and $<2 \mathrm{wk}$. Overall, 17 of 35 (49\%) Ureaplasma-positive infants, 10 of 31 (32\%) bacteria-positive infants, and 18 of 56 (32\%) bacteria-negative infants were in the group with $M V \geq 2$ wks (Figure 1a), and the other infants were in the group with $\mathrm{MV}<2 \mathrm{wk}$ (Figure 1b). In both these groups, the median KL-6 levels in the Ureaplasmapositive infants increased time-dependently after birth and, at $2 \mathrm{wk}$ of age, these levels were significantly higher than in the bacteria-negative infants (Figure 1a,b). Furthermore, in the analysis of the group with $M V \geq 2 \mathrm{wk}$, the median KL- 6 level at
4 wk of age was significantly higher in the Ureaplasma-positive infants than in the bacteria-negative infants (Figure 1a). On the other hand, in the analysis of the group with $\mathrm{MV}<2 \mathrm{wk}$, the median KL-6 levels at 4 wk of age were not significantly different among the Ureaplasma-positive, bacteria-negative, and bacteria-positive infants (Figure 1b).

\section{DISCUSSION}

In this study, we investigated whether the morbidity related to BPD may be affected by antenatal exposure to Ureaplasma

Table 2 The results of a univariate analysis between predictor variables and the development of moderate/severe BPD among all study infants

\begin{tabular}{|c|c|c|c|c|c|}
\hline \multirow[b]{2}{*}{ Factor } & \multirow{2}{*}{$\frac{\text { Total }}{N}$} & \multicolumn{2}{|c|}{ Moderate/severe BPD } & \multirow[b]{2}{*}{$95 \% \mathrm{Cl}$} & \multirow[b]{2}{*}{$P$ value } \\
\hline & & $n(\%)$ & OR & & \\
\hline & 122 & $31(25 \%)$ & & & \\
\hline $\mathrm{GA}(w k)$ & & & 0.53 & $(0.36-0.75)$ & $<0.0001^{* *}$ \\
\hline BW $(100 \mathrm{~g})$ & & & 0.54 & $(0.41-0.69)$ & $<0.0001^{* *}$ \\
\hline$Z$ score & & & 0.70 & $(0.45-0.97)$ & $0.045^{*}$ \\
\hline \multicolumn{6}{|l|}{ Male gender } \\
\hline No & 61 & $15(25 \%)$ & Reference & - & - \\
\hline Yes & 61 & $16(26 \%)$ & 1.09 & $(0.48-2.50)$ & 0.83 \\
\hline \multicolumn{6}{|l|}{ CS } \\
\hline No & 30 & $10(33 \%)$ & Reference & - & - \\
\hline Yes & 92 & $21(23 \%)$ & 0.59 & $(0.24-1.49)$ & 0.26 \\
\hline \multicolumn{6}{|l|}{$P D A$} \\
\hline No & 67 & $13(19 \%)$ & Reference & - & - \\
\hline Yes & 55 & $18(33 \%)$ & 2.02 & $(0.89-4.56)$ & 0.092 \\
\hline \multicolumn{6}{|l|}{ RDS } \\
\hline No & 40 & $4(10 \%)$ & Reference & - & - \\
\hline Yes & 82 & $27(33 \%)$ & 4.42 & $(1.75-17.7)$ & $0.004^{* *}$ \\
\hline \multicolumn{6}{|c|}{ Chorioamnionitis $^{a}$} \\
\hline No & 65 & $17(26 \%)$ & Reference & - & - \\
\hline Grade 1 & 21 & $2(9.5 \%)$ & 0.30 & $(0.07-1.89)$ & 0.30 \\
\hline$\geq$ Grade 2 & 30 & $12(40 \%)$ & 1.88 & $(0.76-5.02)$ & 0.16 \\
\hline \multicolumn{6}{|l|}{ Ureaplasma } \\
\hline No & 87 & $17(20 \%)$ & Reference & - & - \\
\hline Yes & 35 & $14(40 \%)$ & 2.75 & $(1.72-9.80)$ & $0.006^{*}$ \\
\hline \multicolumn{6}{|c|}{ Other bacteria } \\
\hline No & 91 & $25(27 \%)$ & Reference & - & - \\
\hline Yes & 31 & $6(19 \%)$ & 0.63 & $(0.22-1.74)$ & 0.42 \\
\hline \multicolumn{6}{|l|}{$M V$} \\
\hline$<1 \mathrm{wk}$ & 54 & $4(7.4 \%)$ & Reference & - & - \\
\hline $\begin{array}{l}\geq 1 \mathrm{wk}, \\
<2 \mathrm{wk}\end{array}$ & 23 & $3(13 \%)$ & 1.89 & $(0.65-33.7)$ & 0.25 \\
\hline$\geq 2 w k$ & 45 & $24(53 \%)$ & 14.3 & (3.10-45.6) & $<0.0001^{* *}$ \\
\hline
\end{tabular}

BPD, bronchopulmonary dysplasia; BW, birth weight; Cl, confidence interval; CS, cesarean section; GA, gestational age; MV, mechanical ventilation; $N$, number of infants analyzed; $n(\%)$, number (proportion) of infants with moderate/severe BPD among study infants; $\mathrm{OR}$, odds ratio; PDA, patent ductus arteriosus; RDS, respiratory distress syndrome. aThe number of infants investigated was 116. ${ }^{*} P<0.05$; ${ }^{*} P<0.005$. 
Table 3 The results of a multivariate logistic regression analysis between predictor variables and the development of moderate/ severe BPD among all study infants

\begin{tabular}{llcl}
\hline \multicolumn{1}{r}{ Factor } & aOR & $95 \% \mathrm{Cl}$ & $P$ value \\
\hline GA (wk) & 0.53 & $(0.33-0.81)$ & $0.003^{* *}$ \\
Z score & 0.56 & $(0.35-0.89)$ & $0.041^{*}$ \\
Ureaplasma & 2.58 & $(0.57-6.89)$ & 0.12 \\
MV $\geq 2$ wk & 4.60 & $(1.52-6.10)$ & $0.005^{*}$ \\
RDS & 2.91 & $(0.43-15.2)$ & 0.33 \\
PDA & 1.10 & $(0.34-3.70)$ & 0.87 \\
\hline
\end{tabular}

aOR, adjusted $\mathrm{OR} ; \mathrm{Cl}$, confidence interval; $\mathrm{GA}$, gestational age; $\mathrm{MV}$, mechanical ventilation; $\mathrm{OR}$, odds ratio; $\mathrm{PDA}$, patent ductus arteriosus; $\mathrm{RDS}$, respiratory distress syndrome. ${ }^{*} P<0.05 ;{ }^{* *} P<0.005$

Table 4 The results of an interaction analysis between Ureaplasma species and prolonged mechanical ventilation for the development of moderate/severe BPD in a multivariate logistic-regression model

\begin{tabular}{|c|c|c|c|}
\hline Factor & $\mathrm{aOR}$ & $95 \% \mathrm{Cl}$ & $P$ value \\
\hline GA & 0.51 & $(0.35-0.78)$ & $0.001^{* *}$ \\
\hline$Z$ score & 0.57 & $(0.28-0.92)$ & $0.025^{*}$ \\
\hline RDS & 2.95 & $(0.61-11.2)$ & 0.17 \\
\hline PDA & 1.37 & $(0.41-4.76)$ & 0.61 \\
\hline
\end{tabular}

Model 1

\begin{tabular}{|c|c|c|c|}
\hline $\begin{array}{l}\text { Ureaplasma-negative } \times \mathrm{MV} \\
<2 \mathrm{wk}(n=59)\end{array}$ & Reference & - & - \\
\hline $\begin{array}{l}\text { Ureaplasma-positive } \times \mathrm{MV} \\
<2 \mathrm{wk}(n=18)\end{array}$ & 0.38 & $(0.010-1.58)$ & 0.14 \\
\hline $\begin{array}{l}\text { Ureaplasma-negative } \times \mathrm{MV} \\
\geq 2 \mathrm{wk}(n=28)\end{array}$ & 2.15 & $(1.20-6.46)$ & $0.011^{*}$ \\
\hline $\begin{array}{l}\text { Ureaplasma-positive } \times \mathrm{MV} \\
\geq 2 \mathrm{wk}(n=17)\end{array}$ & 8.95 & $(2.12-73.5)$ & $0.001^{* *}$ \\
\hline \multicolumn{4}{|l|}{ odel 2} \\
\hline $\begin{array}{l}\text { Ureaplasma-negative } \times \mathrm{MV} \\
\geq 2 \mathrm{wk}(n=28)\end{array}$ & Reference & - & - \\
\hline $\begin{array}{l}\text { Ureaplasma-positive } \times \mathrm{MV} \\
\geq 2 \mathrm{wk}(n=17)\end{array}$ & 4.17 & $(1.62-44.1)$ & $0.009^{* *}$ \\
\hline
\end{tabular}

The interaction between the duration of $\mathrm{MV}$ and antenatal exposure to Ureaplasma species was analyzed by a logistic-regression analysis after controlling for GA, Z score, RDS, and PDA. Each aOR for the risk of moderate/severe BPD was estimated in the respective four groups of infants (with $M V \geq 2$ wk or $<2$ wk \pm Ureaplasma species), after being adjusted with the OR for Ureaplasma-negative $\times M V<2$ wk (model 1 ) or Ureaplasma-negative $\times M V \geq 2 w k$ (model 2), respectively.

$\mathrm{aOR}$, adjusted $\mathrm{OR} ; \mathrm{Cl}$, confidence interval; $\mathrm{GA}$, gestational age; $\mathrm{MV}$, mechanical ventilation; $\mathrm{OR}$, odds ratio; $\mathrm{PDA}$, patent ductus arteriosus; $R D S$, respiratory distress syndrome. ${ }^{*} P<0.05 ;{ }^{*} P<0.005$

species or other bacteria and whether the exposure to such bacteria would modulate the respiratory outcome of BPD in conjunction with subsequent MV. Our findings indicate that immature, preterm infants who are antenatally exposed to Ureaplasma species (but not infants exposed to other bacteria) have an increased risk of adverse respiratory outcome of BPD, in synergy with prolonged $\mathrm{MV}$ of $\geq 2 \mathrm{wk}$ after birth.

The relationship between antenatal infection and subsequent development of BPD has been debated for more than two decades $(3-5,19)$. Although the underlying mechanism is yet
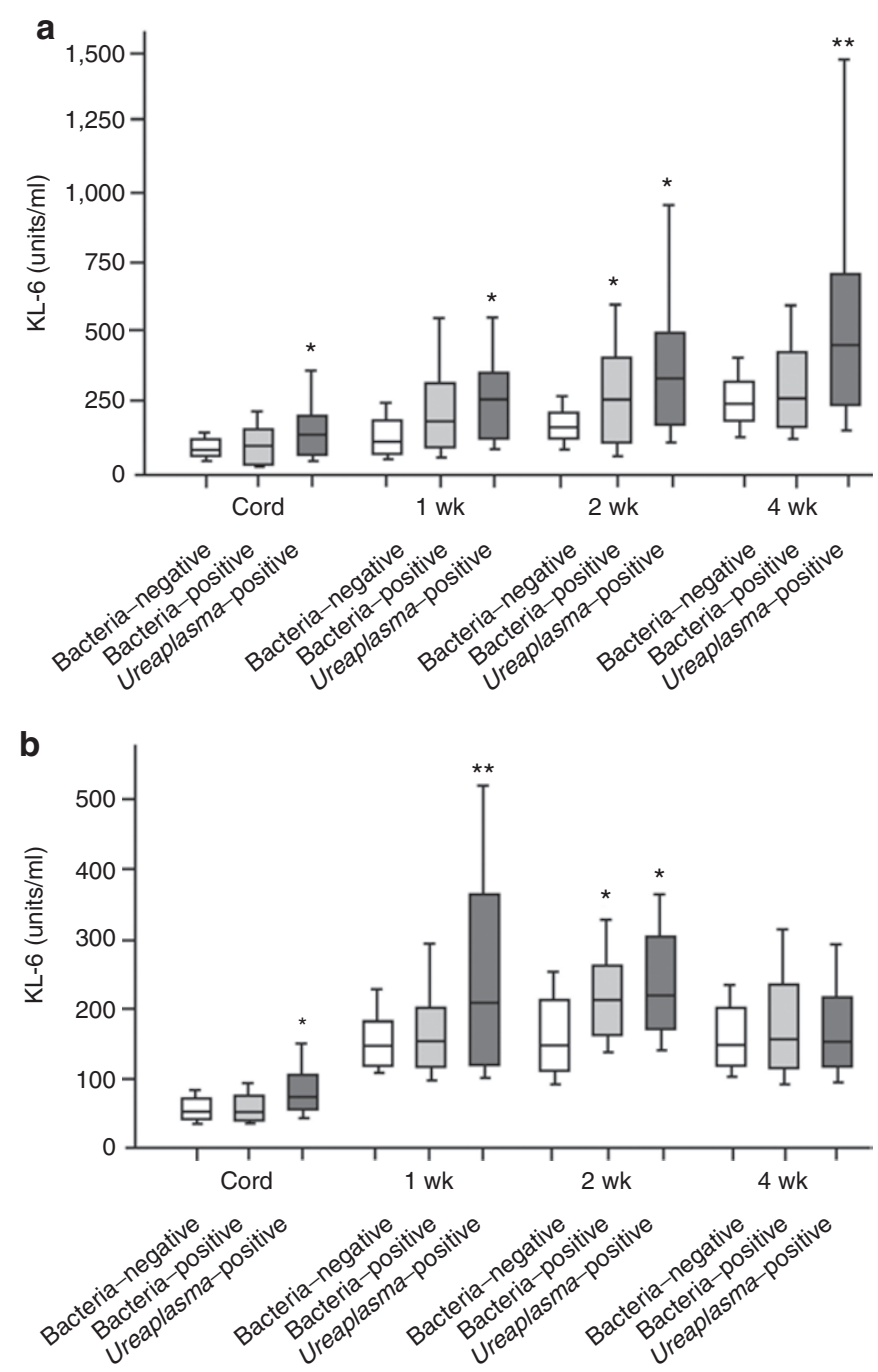

Figure 1. Comparison of median KL-6 levels within 2 wk of age. (a) A comparison among infants with $M V \geq 2 \mathrm{wk}$. The numbers of infants investigated (10th-90th percentiles) were 18 (15), 10 (8), and 17 (13) in the bacteria-negative subgroup, the bacteria-positive subgroup, and the Ureaplasma-positive group, respectively. (b) Comparison among infants with $M V<2$ wk. The numbers of infants investigated (10th-90th percentiles) were 38 (30), 21 (16), and 18 (14) in the bacteria-negative subgroup, the bacteria-positive subgroup, and the Ureaplasma-positive group, respectively. ${ }^{*} P<0.05,{ }^{* *} P<0.005$ vs. the bacteria-negative subgroup at each time point, analyzed using the Mann-Whitney U-test. The differences in the KL- 6 levels between groups were analyzed by two-way repeated-measures ANOVA ((a): bacteria-negative vs. bacteriapositive, $P=0.041$; bacteria-negative vs. Ureaplasma-positive, $P=0.009$; (b): bacteria-negative vs. bacteria-positive, $P=0.010$; bacteria-negative vs. Ureaplasma-positive, $P=0.009$ ). Box plots show the median values with interquartile range for $\mathrm{KL}-6$, and whisker plots show the 10th and 90th percentiles of plasma KL-6. MV, mechanical ventilation.

to be determined, recent experimental studies have provided clues. In animal studies, the intrauterine injection of endotoxin or Ureaplasma parvum resulted in enhanced inflammation and morphologic change in the premature lung, leading to subsequent abnormalities in lung development $(5,20)$. A study in a baboon model clarified that intrauterine infection with Ureaplasma species contributes to early lung fibrosis in conjunction with MV for $14 \mathrm{~d}$ (21). An experimental study using 
alveolar type II cells also showed that exposure to chorioamnionitis inhibits alveolar epithelial repair after lung injury (22). Taken together, these findings indicate that antenatal infection with either Ureaplasma species or other bacteria may inhibit alveolar epithelial repair after lung injury and remodel lung architecture, leading to developmental abnormalities. A recent clinical study reported that the placental and/or fetal inflammatory response has a protective effect against the development of BPD, presumably because of the reduced incidence of RDS and associated reduced need for MV (23). On the other hand, Marter et al. reported that the risk of BPD was higher in the presence of chorioamnionitis in conjunction with MV of $>7 \mathrm{~d}$ or postnatal sepsis (24). It has therefore been postulated that chorioamnionitis in itself is not a risk factor, and it may even have a protective effect against BPD, whereas subsequent prolonged MV or postnatal infection/inflammation may increase the risk for adverse lung development, thereby leading to BPD. In the case of antenatal infection, signs of fetal inflammation, reflecting a more serious inflammatory state in the fetus, are thought to provoke an impaired surfactant response that is a characteristic of ongoing BPD $(25,26)$. Therefore, a priming microorganism or its related signaling during antenatal infection, together with MV soon after birth may induce lung inflammation, alter the architecture of the immature lung, and compromise postnatal lung development.

We recently found that preterm newborns who tested positive for bacterial 16S rRNA in gastric fluid specimens obtained soon after birth had a higher risk of developing severe BPD (16). However, we could not clarify which microorganism (Ureaplasma species or other bacteria) was most frequently associated with severe BPD, and how such a microorganism induced lung injury leading to BPD. In this study, we intended to identify whether antenatal exposure to Ureaplasma species or other bacteria provokes lung injury leading to BPD; we also sought to investigate whether this process, if present, was induced prior to birth and thereafter enhanced merely by the exposure itself, or whether there was an interaction between prior exposure to bacteria and MV initiated soon after birth.

A univariateanalysisindicated that the presence of Ureaplasma species (but not the presence of other bacterial species) in gastric fluid was a significant risk factor along with other potential risk factors. However, the logistic regression analysis showed that the presence of Ureaplasma species was no longer significant (aOR: 2.58, 95\% CI: 0.89-16.3, $P=0.12$ ) after controlling for other potential risk factors including GA, $Z$ score, MV $\geq 2 \mathrm{wk}$, RDS, and patent ductus arteriosus (PDA) (Table 3 ). In another logistic regression analysis, we verified whether antenatal exposure to Ureaplasma species interacts with prolonged $\mathrm{MV}$, and found that these two factors do combine to affect the respiratory outcome of BPD (Table 4). In the analysis of the group with $M V \geq 2 \mathrm{wk}$, the presence of Ureaplasma species was found to enhance the risk of moderate/severe BPD significantly (aOR: 4.17, 95\% CI:1.62-44.1, $P=0.009$ ) after adjusting for the risk relating to Ureaplasma-negative infants. This finding suggests that antenatal exposure to Ureaplasma species and prolonged MV may be synergistically involved in the ongoing process of BPD. Of note, in the analysis of the groups with MV $<2 \mathrm{wk}$, the risk of moderate/severe BPD was much lower in the Ureaplasma-positive infants after adjusting for the risk relating to Ureaplasma-negative infants, although it was not significant (aOR: $0.38,95 \%$ CI: $0.010-1.58, P=0.14$ ). This result may partly correlate with the finding that antenatal infection per se has a protective effect against BPD (23).

To clarify the effect of antenatal exposure to Ureaplasma species or other bacteria on premature lung tissue, we used KL- 6 as a lung injury marker (because serum levels of KL- 6 are known to increase after lung injury) correlating with the severity of respiratory distress in infants with BPD (18). Among the infants with $M V \geq 2 \mathrm{wk}$, the median KL- 6 level in the cord blood of Ureaplasma-positive infants, was higher than in that of the bacteria-negative infants, and this difference in KL-6 levels increased time-dependently after birth (Figure 1a). On the other hand, the median KL-6 levels reached plateaus at 1 or $2 \mathrm{wk}$ in all three groups of infants with $\mathrm{MV}<2 \mathrm{wk}$, and was subsequently lower at $4 \mathrm{wk}$ (Figure $1 \mathrm{~b}$ ). The findings from this analysis suggest that antenatal exposure to Ureaplasma species induces harmful effects in the immature lung prior to birth, and exacerbates lung injury after birth in conjunction with $M V \geq 2 \mathrm{wk}$. Given the fact that an increase in the level of KL-6 is associated with an adverse outcome in BPD, these analysis results support our clinical findings.

Several other researchers have investigated the association between antenatal/postnatal exposure to microorganisms, including Ureaplasma species, and the development of BPD. Previously, van Waarde et al. reported that the presence of Ureaplasma species in tracheal aspirates was significantly associated with the development of BPD, but they found no such correlation after correction for GA (27). In their study, infants on MV with a GA $<42$ wk were enrolled, and BPD was defined as an oxygen requirement for $28 \mathrm{~d}$ after birth. Because their study design allowed them to enroll more infants with a low risk for BPD, it is likely that it underestimated the impact of Ureaplasma species in increasing the risk of developing BPD. Miralles et al. reported in their preliminary study that there was no association between the presence of microbes in neonatal and/or placental specimens and the development of BPD (15). This study has some similarities with ours, but differed in that it was designed to investigate the significance of microbes and not Ureaplasma species. In contrast to the findings of our study, Payne et al. reported that the presence of Ureaplasma species in gastric fluid was not related to the development of BPD, even on the basis of a univariate analysis (28). We cannot pinpoint the reasons for the opposite outcomes in the two studies; however, it would be necessary to verify several institutional factors in neonatal/ maternal management and patient characteristics that affect the prognosis of BPD. For example, as compared with our study, the prevalence of maternal chorioamnionitis was much lower in the study by Payne et al. than in ours (20 vs. $44 \%$ ). Although the prevalence of chorioamnionitis of higher grades was not indicated in their study, it is expected to have been lower than in our study (grade 2 or $3 ; 25 \%$ ) given the overall lower rate of the condition. Because the severity of fetal inflammation/infection and 
the interaction with prolonged MV would affect the prognosis of $\mathrm{BPD}$, the differences between the two samples of study subjects with respect to clinical characteristics may have resulted in the differences in outcome. Colaizy et al. also detected Ureaplasma species in tracheal aspirates of infants and found an association with BPD and/or death (29). Our study was similar to theirs, but our aim was different. We intended to clarify the pathogenetic role of microorganisms, including Ureaplasma species, on the immature fetal lung in antenatal infection; we also intended to identify a reliable candidate for the treatment of developing BPD as early as possible after birth. An analysis using tracheal aspirate specimens makes it difficult to examine such a causal relationship, and often needs a careful interpretation. This is because the analysis of tracheal aspirate specimens may underestimate the rate of Ureaplasma species within $1 \mathrm{wk}$ of life, as we have reported previously (16). Gastric aspirate specimens can be easily obtained soon after birth, even from critically ill infants from whom tracheal aspirate specimens often cannot be obtained. Taken together, our method of using gastric fluid specimens instead of tracheal aspirate specimens is therefore more beneficial in identifying treatment approaches for BPD in the future.

Recently, Ballard et al. performed a double-blind, placebocontrolled, randomized trial of azithromycin in preterm infants who were at risk of BPD and reported an improvement of the $\mathrm{BPD}$ rates in the Ureaplasma subgroup after treatment with azithromycin (30). However, routine use of azithromycin therapy for the prevention of BPD was not recommended because of the lack of a large-scale trial and an optimized treatment regimen. Our findings will contribute to identifying preterm infants at risk of BPD who could benefit the most from the prophylactic administration of azithromycin. These findings could therefore be applicable in future randomized controlled trials.

\section{METHODS}

The study protocol was approved by the ethics committee of Osaka Medical College, and informed consent was obtained from the parents of all the subjects.

\section{Subjects}

Preterm infants with GA $<29$ wk or birth weight $<1,000$ g, admitted to the neonatal intensive care unit of Osaka Medical College Hospital between January 2007 and March 2010, were eligible for this study. The exclusion criteria were: (i) complicated congenital heart diseases; (ii) multiple malformations; or (iii) documented chromosomal anomalies. Infants who died of nonrespiratory causes, those transferred to another facility before reaching a postmenstrual age of $36 \mathrm{wk}$, and those from whom gastric fluid or blood specimens were not available were also excluded. According to the results of gastric fluid tests carried out to determine the presence or absence of the urease gene soon after birth, the enrolled infants were allocated to a Ureaplasma-positive group or a Ureaplasma-negative group. The Ureaplasma-negative infants were further classified into two subgroups, bacteria-positive and bacteria-negative, according to the presence or absence of $16 \mathrm{~S}$ rRNA genes.

Synchronous intermittent MV was initiated in infants who had respiratory distress and, if this failed to maintain the study criteria, high-frequency oscillation ventilation was started. Synchronous intermittent MV was delivered by volume-guaranteed, assist control mode (Babylog 8000; Dräger, Lübeck, Germany), with an initial setting of the tidal volume at $3-5 \mathrm{ml} / \mathrm{kg}$, inspiratory time of $0.3-0.4 \mathrm{~s}$, rate of $40-60 / \mathrm{min}$, maximum peak inflating pressure of $25 \mathrm{~cm} \mathrm{H}_{2} \mathrm{O}$, and positive end expiratory pressure of $5 \mathrm{~cm} \mathrm{H}_{2} \mathrm{O}$. High-frequency oscillation ventilation was delivered using the Babylog 8000 or Calliope a (Metran, Kawaguchi, Japan), with an initial mean airway pressure of $12-14 \mathrm{~cm}$ $\mathrm{H}_{2} \mathrm{O}$. Ventilator settings and oxygen therapy were adjusted to maintain study criteria of $\mathrm{pH} \geq 7.20$, arterial oxygen saturation as measured by pulse oximetry $\left(\mathrm{SpO}_{2}\right)$ between 88 and $95 \%$, and partial pressure of carbon dioxide $\left(\mathrm{pCO}_{2}\right)$ between 40 and $60 \mathrm{mmHg}$.

BPD was defined in accordance with the National Institutes of Health consensus definition for infants with GA $<32 \mathrm{wk}$ (fraction of inspired oxygen $\left(\mathrm{FiO}_{2}\right)>0.21$ for at least $\left.28 \mathrm{~d}\right)$. At a postmenstrual age of $36 \mathrm{wk}$, the infants were classified into the following three subgroups: mild $\mathrm{BPD}\left(\mathrm{FiO}_{2}=0.21\right)$, moderate $\mathrm{BPD}\left(0.21<\mathrm{FiO}_{2}<0.30\right)$, and severe $\mathrm{BPD}\left(\mathrm{FiO}_{2} \geq 0.30\right.$ and/or positive pressure assistance) (31). Intubated infants who needed $\mathrm{FiO}_{2} \geq 0.4$ to maintain $\mathrm{SpO}_{2} \geq 90 \%$ and had typical radiographic features of RDS were diagnosed as having RDS. All infants on MV who required $\mathrm{FiO}_{2}>0.60$ to maintain $\mathrm{SpO}_{2}$ $>88 \%$ because of respiratory failure after the first week of life received low-dose dexamethasone $(0.89 \mathrm{mg} / \mathrm{kg}$ over $10 \mathrm{~d})$, as reported previously (32). If these ventilated infants required $\mathrm{FiO}_{2} \geq 0.60$ to maintain $\mathrm{SpO}_{2}>88 \%$ despite the initial low-dose dexamethasone treatment, further dexamethasone treatment was administered over $7 \mathrm{~d}$ $(0.50 \mathrm{mg} / \mathrm{kg} / \mathrm{d}$ for $3 \mathrm{~d}, 0.25 \mathrm{mg} / \mathrm{kg} / \mathrm{d}$ for $3 \mathrm{~d}$, and $0.10 \mathrm{mg} / \mathrm{kg} / \mathrm{d}$ for 1 d). Chorioamnionitis was diagnosed histologically if polymorphonuclear leukocytes were seen in the fetal membranes, and its severity was graded according to Blanc (33). Infants who were treated with indomethacin or underwent ligation were diagnosed as having PDA.

\section{Detection of Ureaplasma species and other bacteria}

We inserted nasogastric tubes into all the infants to collect gastric fluids within the first hour after birth and used them for the extraction of DNA, as reported previously (16). The bacterial $16 \mathrm{~S}$ rRNA gene was detected using the methods described previously $(15,16)$. Briefly, the extracted DNA was amplified by PCR using the FD1 (AGA GTT TGA TCC TGG CTC AG) and rP1 (ACG G(T/A/C)T ACC TTG TTA CGA CTT) primers. After PCR amplification, $1 \mu$ of the reaction product was re-amplified using another pair of primers, FD1 and rD2 (G(T/A)A TTA CCG CGG C(G/T)G CTG). For detection of Ureaplasma species, the extracted DNA was amplified by PCR with the primer pair U5 (CAA TCT GCT CGT GAA GTA TTA C) and U4 (ACG ACG TCC ATA AGC $\mathrm{AAC}$ T) to detect the urease gene, as reported previously (34).

\section{Measurement of KL-6}

Blood samples were collected from cord blood at birth and also by venipuncture at 1,2 , and $4 \mathrm{wk}$ of age, after parental consent was obtained. The blood samples were immediately centrifuged at $3,000 \mathrm{~g}$ for $10 \mathrm{~min}$ at $4^{\circ} \mathrm{C}$ to obtain plasma, which was stored at $-80^{\circ} \mathrm{C}$ until analysis. The serum KL-6 levels were measured using a chemiluminescent enzyme immunoassay kit (Eidia, Tokyo, Japan).

\section{Statistical Analysis}

Differences between any two groups were assessed using the MannWhitney U-test for continuous variables or Fisher's exact test for categorical data. Differences among three groups were assessed using the Kruskal-Wallis test for continuous variables or the $\chi^{2}$ test for categorical data. The variables associated with moderate/severe BPD in the univariate analysis $(P<0.10)$ were included in a logisticregression analysis. Birth weight was not included because of its close correlation with GA $\left(\chi^{2}=0.79\right)$. The first logistic-regression model included GA, $Z$ score, Ureaplasma species, MV $\geq 2 \mathrm{wk}, \mathrm{RDS}$, and PDA (Table 3 ). The second logistic-regression model was constructed to examine the interaction between Ureaplasma species and MV. This model included the GA and $Z$ score as continuous variables, PDA and $\mathrm{RDS}$ as categorical variables, and MV ( $<2 \mathrm{wk}$ or $\geq 2 \mathrm{wk}) \pm$ Ureaplasma species as a discrete variable (Table 4). For the comparison of KL-6 levels between groups, two-way repeated-measures ANOVA (timedependent change) and the Mann-Whitney U-test (comparison at each time point) were used for the analysis. Data were analyzed using the JMP 9.0 statistical software package (SAS Institute, Cary, NC). In all analyses, $P<0.05$ was considered to be significant.

\section{STATEMENT OF FINANCIAL SUPPORT}

No financial assistance was received to support this study. 


\section{REFERENCES}

1. Kinsella JP, Greenough A, Abman SH. Bronchopulmonary dysplasia. Lancet 2006;367:1421-31.

2. Baraldi E, Filippone M. Chronic lung disease after premature birth. N Engl J Med 2007;357:1946-55.

3. Fujimura M, Takeuchi T, Kitajima H, Nakayama M. Chorioamnionitis and serum IgM in Wilson-Mikity syndrome. Arch Dis Child 1989;64(10 Spec No):1379-83.

4. Watterberg KL, Demers LM, Scott SM, Murphy S. Chorioamnionitis and early lung inflammation in infants in whom bronchopulmonary dysplasia develops. Pediatrics 1996;97:210-5.

5. Jobe AH, Ikegami M. Antenatal infection/inflammation and postnatal lung maturation and injury. Respir Res 2001;2:27-32.

6. Kundsin RB, Driscoll SG, Monson RR, Yeh C, Biano SA, Cochran WD. Association of Ureaplasma urealyticum in the placenta with perinatal morbidity and mortality. N Engl J Med 1984,310:941-945.

7. Waites KB, Katz B, Schelonka RL. Mycoplasmas and ureaplasmas as neonatal pathogens. Clin Microbiol Rev 2005;18:757-89.

8. Wang EE, Frayha H, Watts J, et al. Role of Ureaplasma urealyticum and other pathogens in the development of chronic lung disease of prematurity. Pediatr Infect Dis J 1988;7:547-51.

9. Cassell GH, Waites KB, Crouse DT, et al. Association of Ureaplasma urealyticum infection of the lower respiratory tract with chronic lung disease and death in very-low-birth-weight infants. Lancet 1988;2:240-5.

10. Sánchez PJ, Regan JA. Ureaplasma urealyticum colonization and chronic lung disease in low birth weight infants. Pediatr Infect Dis J 1988;7:542-6.

11. Kafetzis DA, Skevaki CL, Skouteri V, et al. Maternal genital colonization with Ureaplasma urealyticum promotes preterm delivery: association of the respiratory colonization of premature infants with chronic lung disease and increased mortality. Clin Infect Dis 2004;39:1113-22.

12. Cordero L, Ayers LW, Davis K. Neonatal airway colonization with gramnegative bacilli: association with severity of bronchopulmonary dysplasia. Pediatr Infect Dis J 1997;16:18-23.

13. Speer CP. Inflammation and bronchopulmonary dysplasia: a continuing story. Semin Fetal Neonatal Med 2006;11:354-62.

14. Kramer BW, Kallapur S, Newnham J, Jobe AH. Prenatal inflammation and lung development. Semin Fetal Neonatal Med 2009;14:2-7.

15. Miralles R, Hodge R, McParland PC, et al. Relationship between antenatal inflammation and antenatal infection identified by detection of microbial genes by polymerase chain reaction. Pediatr Res 2005;57:570-7.

16. Oue S, Hiroi M, Ogawa S, et al. Association of gastric fluid microbes at birth with severe bronchopulmonary dysplasia. Arch Dis Child Fetal Neonatal Ed 2009;94:F17-22.

17. Kohno N. Serum marker KL-6/MUC1 for the diagnosis and management of interstitial pneumonitis. J Med Invest 1999;46:151-8.

18. Ogihara T, Hirano K, Morinobu T, et al. Plasma KL-6 predicts the development and outcome of bronchopulmonary dysplasia. Pediatr Res 2006;60:613-8.

19. Been JV, Zimmermann LJ. Histological chorioamnionitis and respiratory outcome in preterm infants. Arch Dis Child Fetal Neonatal Ed 2009;94:F218-25.
20. Collins JJ, Kallapur SG, Knox CL, et al. Inflammation in fetal sheep from intra-amniotic injection of Ureaplasma parvum. Am J Physiol Lung Cell Mol Physiol 2010;299:L852-60.

21. Viscardi RM, Atamas SP, Luzina IG, et al. Antenatal Ureaplasma urealyticum respiratory tract infection stimulates proinflammatory, profibrotic responses in the preterm baboon lung. Pediatr Res 2006;60: 141-6.

22. Been JV, Zimmermann LJ, Debeer A, Kloosterboer N, van Iwaarden JF. Bronchoalveolar lavage fluid from preterm infants with chorioamnionitis inhibits alveolar epithelial repair. Respir Res 2009;10:116.

23. Lahra MM, Beeby PJ, Jeffery HE. Intrauterine inflammation, neonatal sepsis, and chronic lung disease: a 13-year hospital cohort study. Pediatrics 2009;123:1314-9.

24. Van Marter LJ, Dammann O, Allred EN, et al. Chorioamnionitis, mechanical ventilation, and postnatal sepsis as modulators of chronic lung disease in preterm infants. J Pediatr 2002;140:171-6.

25. Been JV, Rours IG, Kornelisse RF, Jonkers F, de Krijger RR, Zimmermann LJ. Chorioamnionitis alters the response to surfactant in preterm infants. J Pediatr 2010;156:10-15.e1.

26. Lee HJ, Kim EK, Kim HS, Choi CW, Kim BI, Choi JH. Chorioamnionitis, respiratory distress syndrome and bronchopulmonary dysplasia in extremely low birth weight infants. J Perinatol 2011;31:166-70.

27. van Waarde WM, Brus F, Okken A, Kimpen JL. Ureaplasma urealyticum colonization, prematurity and bronchopulmonary dysplasia. Eur Respir J 1997;10:886-90

28. Payne MS, Goss KC, Connett GJ, et al. Molecular microbiological characterization of preterm neonates at risk of bronchopulmonary dysplasia. Pediatr Res 2010;67:412-8

29. Colaizy TT, Morris CD, Lapidus J, Sklar RS, Pillers DA. Detection of ureaplasma DNA in endotracheal samples is associated with bronchopulmonary dysplasia after adjustment for multiple risk factors. Pediatr Res 2007;61(5 Pt 1):578-83.

30. Ballard HO, Shook LA, Bernard P, et al. Use of azithromycin for the prevention of bronchopulmonary dysplasia in preterm infants: a randomized, double-blind, placebo controlled trial. Pediatr Pulmonol 2011;46:111-8

31. Jobe AH, Bancalari E. Bronchopulmonary dysplasia. Am J Respir Crit Care Med 2001;163:1723-9.

32. Doyle LW, Davis PG, Morley CJ, McPhee A, Carlin JB; DART Study Investigators. Low-dose dexamethasone facilitates extubation among chronically ventilator-dependent infants: a multicenter, international, randomized, controlled trial. Pediatrics 2006;117:75-83.

33. BLANC WA. Amniotic infection syndrome; pathogenesis, morphology, and significance in circumnatal mortality. Clin Obstet Gynecol 1959;2:705-34

34. Kotecha S, Hodge R, Schaber JA, Miralles R, Silverman M, Grant WD. Pulmonary Ureaplasma urealyticum is associated with the development of acute lung inflammation and chronic lung disease in preterm infants. Pediatr Res 2004;55:61-8. 